\title{
Miradas argumentativas y filosóficas ante casos difíciles $^{*}$
}

\section{An argumentative and philosophical approach before "hard cases"}

\author{
Renato Rabbi-Baldi Cabanillas \\ ${ }^{1}$ Universidad de Buenos Aries \\ Orcid: https://orcid.org/0000-0001-7347-4205 \\ DOI: https://doi.org/10.22235/rd.v0i19.1775 \\ Conferencia
}

Resumen: A partir del fin de la Segunda Guerra Mundial se observa un marcado declive del concepto positivista de ciencia jurídica en favor de un modelo retórico-tópico que se apoya en la noción de razón práctica inspirada en Aristóteles. Lo dicho ha puesto en el centro de la escena el officium argumentativo en orden a determinar el sentido del derecho y, tras de ello, un amplio desarrollo de teorías argumentativas que aspiran a justificar racionalmente las decisiones judiciales. En este trabajo, tras señalar ese "giro", ejemplificándolo con diversos supuestos extraídos de la práctica tribunalicia -principalmente de la jurisprudencia de la Corte Suprema de Justicia Argentina-, se efectúa un análisis de los distintos tipos de jueces y de la diversa complejidad de los casos judiciales que tienen a observarse en la práctica. Dicha clasificación tiene directa incidencia en la manera cómo afrontar los cada vez más extendidos "casos difíciles" que se advierten no solo en sociedades heterogéneas, sino en ámbitos de mayor consenso,

Recibido: 10/12/18. Evaluado 01/02/19. Aceptado: 02/02/19.

\footnotetext{
*Conferencia escrita para ser leída en el Workshop de Filosofía del Derecho y, posteriormente, corregida para su publicación.

Renato Rabbi-Baldi Cabanillas: Abogado y doctor en Derecho, titular de Teoría General y Filosofía del Derecho (UBA) y juez de la Cámara Federal de Apelaciones, Salta. Actual presidente de la Asociación Argentina de Filosofía del Derecho. renatorabbibaldi@gmail.com
} 
entre otras razones, por el creciente desarrollo de un estado constitucional de derecho en el que desempeñan un papel predominante los derechos fundamentales, los que, al estructurarse como principios jurídicos que poseen una indudable naturaleza moral, requieren de un exigente despliegue argumentativo.

Palabras claVe: argumentación; teoría de la argumentación; tipos de jueces y tipos de casos judiciales; casos difíciles; estado constitucional de derecho, principios jurídicos SUmmarY: Since the end of the Second World War there is a marked decline in the positivist concept of legal science in favor of a rhetorical-topical model that relies on the notion of practical reason inspired by Aristotle. This has put in the center of the scene the argumentative Officium in order to determine the sense of the right and, after that, a broad development of argumentative theories that aspire to rationally justify the judicial decisions. In this work, after pointing out this "Giro", with various assumptions extracted from the court practice -mainly from the jurisprudence of the Argentine Supreme Court-, an analysis of the different types of judges is carried out and the Different complexity of the judicial cases that have to be observed in practice. This classification has a direct impact on how to deal with the increasingly widespread "difficult cases" that are warned not only in heterogeneous societies, but in areas of greater consensus, among other reasons, by the growing development of a State Constitutional law in which fundamental rights play a predominant role, which, when structured as legal principles that have an undoubted moral nature, require a demanding argumentative deployment.

KEY-WORDS: argumentation; theorie of the argumentation; tipe of judges and of judicial cases; hard cases; constitucional state of law; juridical 


\section{INTRODUCCIÓN}

Se sabe que, a partir del fin de la Segunda Guerra Mundial, el "concepto positivista de ciencia”, tal y como gustaba denominarlo Karl Larenz, es objeto de crítica tanto desde la esfera de su fundamentación como desde el ámbito metodológico.

Lo primero -aquello que Kant caracterizó como la esfera del quid ius, es decir, del qué y el porqué del derecho- se aprecia a través de, cuanto menos, tres dimensiones necesariamente convergentes:

a) la rehabilitación de la pregunta acerca del significado de la justicia, lo que implicó su "readmisión" entre las cuestiones de índole científica que, por ende, merecía ser materia de reflexión. Los trabajos -de muy diverso contenido- de E. Brunner, en la década del cincuenta o de J. Rawls a principios de los setenta constituyen un buen ejemplo de lo expuesto;

b) la consideración de los derechos humanos, es decir, de ciertas dimensiones básicas de la persona que, como expresa la Declaración Universal de 1948 son consecuencia de la "dignidad intrínseca y de los derechos iguales e inalienables de todos los miembros de la familia humana", como fundamento de todo el ordenamiento jurídico, y la creciente positivación de aquéllos tanto en los ordenamientos jurídicos nacionales como en el internacional.

c) el papel funcional del derecho, es decir, la consideración de que ya no interesa la "estructura" del sistema, sino, precisamente, su "función”, el para qué de éste. Los estudios de N. Bobbio, a mediados de la década del sesenta son paradigmáticos de esta postura.

Por su parte, lo segundo se aprecia por conducto de la especial atención que se dispensa al modus operandi de los tribunales; al proceso judicial. A este respecto, se advierten diversas propuestas que, dicho de forma general, tienden a reemplazar a una concepción sistemático-dogmática del derecho moldeada bajo aquél concepto positivista de ciencia, por una de cuño problemática fundada en un horizonte dialéctico o dialógico, es decir, estructu- 
rada a partir de argumentos y contraargumentos. Sobre el particular, una reflexión de H.LA. Hart parece dar adecuada cuenta de esta situación cuando señala que "el énfasis puesto por los anti-positivistas hacia la naturaleza del proceso judicial puede sorprender a los juristas y filósofos del derecho europeos. Siempre -pienso- ha sido la característica más llamativa de la Teoría del derecho americano pensar que una comprensión clara del proceso judicial es la mejor clave para el entendimiento de lo que es el derecho, y pensar también que se obtiene mayor luz de orientar la atención no a las claras reglas establecidas por el sistema jurídico y a la manera en que funcionan fuera de los tribunales, sino más bien a los controvertidos casos difíciles que son aquellos en los que cualificados juristas pueden estar en desacuerdo sobre lo que es el derecho en algún punto" ${ }^{2}$.

Pues bien, entre dichas propuestas, se destacan las siguientes:

a) La de matriz aristotélica, caracterizada por la rehabilitación de la razón práctica como guía para discernir el derecho en un contexto en el que se recupera la consideración retórica del Estagirita sobre esta materia. T. Viehweg; Ch. Perelman: M. Villey o Arthur Kaufmann, pueden ser ejemplos de esa postura;

b) La hermenéutica filosófica con su holística consideración del fenómeno interpretativo, a partir de los trabajos de Husserl; M. Heidegger y, de modo especial por su vínculo con el derecho, H.G. Gadamer; J. Esser; el citado Kaufmann; W. Hassemer; A. Ollero o F. D’ Agostino, entro otros;

c) Los planteamientos de corte más analítico, aunque preocupados por dotar a la actividad interpretativa de un vigoroso conjunto de reglas argumentativas que aseguren la racionalidad de la decisión jurídica, como los de J. Wróblewski; G. Tarello; R. Alexy o A. Aarnio;

d) La consideración de que el sistema jurídico no sólo está dotado de reglas sino, además, de principios, lo cual revela no solo el apartamiento de la "rule book conception", tal y como es señalado por Dworkin en su conocida polémica con Hart, sino que, además, dada la íntima vinculación de aquellos con la moral, su presencia procedan de una práctica del foro; del ethos de una sociedad-, o de a partir de ciertos criterios perceptibles a escala universal a partir de exigencias básicas de las personas, como se lee, por ejemplo, en el Preámbulo del Pacto de San José de Costa Rica), entraña el quiebre del paradigma positivista basado sobre la férrea separación entre derecho y moral, como es puesto de relieve, además de por el citado Dworkin, con anterioridad, por J. Esser en su conocida polémica H. Kelsen en los tempranos sesenta;

\footnotetext{
2 Herbert Hart, “El nuevo desafío al positivismo jurídico”, Sistema Nº 36 (mayo 1980), Madrid, (del inglés por L. Hierro, F. Laporta y J. R. Páramo), 6. El énfasis es del original.
} 
e) La "juridificación” de la las constituciones nacionales de los estados, fenómeno que se aprecia en las países europeos (no así en los Estados Unidos y en la Argentina, donde este perspectiva se da por descontado desde un primer momento) y que contribuye a dar cabida, al interior de todo ordenamiento jurídico, a las valoraciones morales y políticas que entrańa todo texto constitucional, las cuales, de esta forma, pasan a integrar plenamente el sistema de derecho de esos estados.

Pues bien, el objeto de este papel, en el marco de un encuentro dedicado a la Argumentación e Interpretación jurídicas, es plantear, en primer lugar, la creciente relevancia de la argumentación a fin de discernir el sentido del derecho, lo que va de la mano de una de las notas típicas del pensamiento de razón práctica, tal y como es configurado por Aristóteles hace casi 2500 años (II). Dicha relevancia pone en el centro de la escena a la judicatura, la que adquiere un protagonismo ausente bajo un paradigma clásicamente positivista. Emergen entonces tres posibles modelos de jueces que actúan en paralelo a tres posibles esquemas de casos judiciales. Un repaso de esas características ocupa el punto III. De su examen se propone un modelo más apropiado de judicatura y de argumentación, todo lo cual será examinado en el apartado IV a partir de un ejemplo jurisprudencial.

\section{RELEVANCIA DEL OFFICIUM ARGUMENTATIVO}

El pensamiento de la razón práctica plantea, antes que nada, la inexorable vinculación entre teoría y práctica en el ámbito jurídico. Por de pronto, el reconocimiento de la dimensión teórica de la práctica, la que es sumamente ostensible cuando, v. gr., los tribunales constitucionales asumen decisiones de trascendencia: piénsese en cuestiones concernientes al estatuto de la vida o de la muerte o los límites entre las facultades estatales y la autonomía privada ${ }^{3}$. Pero, necesario correlato de lo anterior, la dimensión práctica de la teoría pues, para seguir con los ejemplos recién citados, no se comprende cabalmente el alcance de la vida humana o su modo de ejercicio, sino a partir de problemas concretos en torno de estas cuestiones.

\footnotetext{
3 Para la Argentina, considérenselas decisiones del Alto Tribunal en las causas “Bahamondez" (Fallos: 316:479) y "Albarracini" (Fallos: 335:799), sobre la autorización o no de prácticas médicas basadas en fundamentos religiosos con consecuencias para la propia vida del peticionante, o "Arriola" (Fallos: 332:1963), sobre la permisión del consumo de estupefacientes a título personal.
} 
Esta perspectiva revela un inevitable officium argumentativo. Hablar de argumentación, en efecto, entraña mentar una razón práctica, es decir, una razón que corrige; que rectifica (de ahí la conocida expresión medieval "recta ratio", que sintetiza -nada redundantemente, como se le reprochó en la modernidad ${ }^{4}$ - la enseñanza de Aristóteles; que se abre camino entre los hechos; normas; razones (y sinrazones) de las partes. Se trata, en fin, de una razón que argumenta en torno de un problema o, mejor, de problemas.

Lo recién dicho supone una apreciación rica en contenidos que conduce a la necesidad y relevancia de la argumentación:

-si bien no se descuida el concurso del elemento sistemático, siguiendo a Josef Esser y a Theodor Viehweg, se acentúa lo que se conoce, desde entonces, como "pensamiento problemático" ${ }^{5}$;

-correlato de lo anterior se advierte la gravitación de la pragmática sobre la sintáctica y la semántica

-asimismo, el "problema” remite a cuestiones de carácter moral. Como explica Francesco Viola, "basta echar una mirada a las sentencias de los jueces constitucionales (sobre todo a los de la Corte Suprema de los Estados Unidos) para que uno se dé cuenta de que se halla delante de debates morales en que el contenido de los valores en juego es más importante la fidelidad a las formulaciones literales de la reglas" ${ }^{\text {. }}$. Así, decisiones como la recién citada sobre la autonomía de la voluntad y el alcance de la intervención estatal en materia de estupefacientes, reenvían al delicado equilibrio entre lo posible y lo deseable; lo mejor y lo tolerable; lo razonable y lo irrazonable; en definitiva, lo justo y lo injusto ${ }^{8}$. Como es obvio, otro tanto cabe predicar de los otros supuestos mencionados (y de cualquiera de

\footnotetext{
4 Cfr Renato Rabbi-Baldi Cabanillas, "El derecho natural como núcleo de la realidad jurídica”, en Las razones del derecho natural. Perspectivas teóricas y metodológicas ante la crisis del positivismo jurídico (Buenos Aires: Ábaco, 2008), 206.

5 Cfr a propósito del primero, Karl Larenz, Metodología de la ciencia del derecho (Barcelona: Ariel, 2001 ), 169. En lo relativo al segundo, cfr Theodor Viehweg, "Algunas consideraciones acerca del razonamiento jurídico", en Tópica y Filosofía del Derecho (Barcelona: Gedisa, 1991); traducción del alemán por R. Zimmerling, con observación preliminar de E. Garzón Valdés; 118. Un ejemplo de la centralidad de este pensamiento se advierte en el modo como principia el nuevo Código Civil y Comercial de la Nación: "los casos que este Código rige deben ser resueltos según las leyes..." (énfasis añadido).

6 Viehweg, "Apuntes para una teoría retórica de la argumentación jurídica”, en Tópica y filosofía..., pp. 167-168.

7 Francesco Viola, "Los derechos humanos: ¿una nueva forma de derecho natural?", en Rabbi-Baldi Cabanillas, Las razones..., nota 3, p. 169.

8 El nuevo Código Civil y Comercial de la Nación parece asumir este paradigma cuando, en el art. $3^{\circ}$, expresa que "el juez debe resolver los asuntos que sean sometidos a su jurisdicción mediante una decisión razonablemente fundada" (énfasis añadido), decisión que acaso deba ser complementada con el art. 10 10,12 y concordantes que sujetan el contenido de la "ley" al "derecho", esto es, a "lo justo", en línea con la clásica enseńanza romano-medieval. Sobre esto, cfr Rabbi-Baldi Cabanillas, "Consideraciones filosófico-jurídicas en torno del Título Preliminar del Proyecto de Código Civil y Comercial de 2012”, en Rivera/Medina, Comentario al Proyecto de Código Civil y Comercial de la Nación 2013 (Buenos Aires: Abeledo Perrot, 2012), 28.
} 
análoga índole), ninguna de cuyas decisiones resultan inocuas, ni neutrales ni, menos, generan indiferencia;

-En efecto; dichas decisiones importan una amplia disparidad de pareceres. Este dato, que es evidente al interior de sociedades homogéneas o más o menos homogéneas (piénsese, por ejemplo, en el mundo Occidental el debate en torno del estatuto del embrión o el tema del aborto), es indiscutido cuando éstas no lo son (reparése, v. gr., a escala planetaria los conocidos supuestos de la ablación del clítoris o de la amputación de un dedo al ladrón) y requiere de una argumentación, la cual será tanto más robusta cuanto mayor sea el ímpetu por obtener una coexistencia no solo posible sino, además, virtuosa.

Ahora bien, ¿por qué se considera que la argumentación es el lugar por excelencia al que converge en la actualidad la atención de los teóricos jurídicos? A mi juicio, esta pregunta está estrechamente ligada al dato de que en la actualidad no se discute el tránsito del llamado Estado de Derecho al Estado Constitucional de Derecho, lo cual ha generado no solamente la expansión de los principios de naturaleza constitucional, sino su creciente operatividad, todo lo cual, como se anticipó, gravita directamente sobre el campo de la argumentación ${ }^{9}$. La realidad jurídica, en efecto, es vista desde hace ya cierto tiempo "sub specie constitutionis", esto es, bajo el prisma de la Constitución, en especial, de sus principios liminares, cuya naturaleza moral conduce a reforzar la relevancia de la argumentación.

$\mathrm{Al}$ respecto, al igual que el ya citado Viola, Alexy ha escrito páginas persuasivas. Así, interesa puntualizar su noción de que "los principios son mandatos de optimización", por lo que, en cuanto tales, exigen 'que algo [el derecho a la vida; a la integridad física; a la libertad de expresión; al honor, etc.] sea realizado en la mayor medida posible dentro de las posibilidades jurídicas y reales existentes”. Y precisa, “el carácter de los principios significa que no se trata simplemente de normas vagas, sino que con ellas", precisamente, "se plantea una tarea de optimización" de aquellos, tarea ésta que "es, en cuanto a la forma, jurídica; en cuanto al fondo, moral" ${ }^{10}$. Desde esa perspectiva, y profundizando el punto de vista del profesor italiano, añade que "toda colisión entre principios puede expresarse como una colisión entre valores y viceversa", por lo que "la única diferencia consiste en que en la colisión entre

\footnotetext{
9 La operatividad de los principios constitucionales -y aún de los valores que dimanan del Preámbulo- ha sido reconocida por la jurisprudencia de la Corte Suprema desde antiguo, como se advierte de los casos "Siri" (Fallos: 239:459) y "Kot" (Fallos: 241:291) y amplia jurisprudencia concordante (conf. causa "Saguir y Dib”, Fallos: 302:1284 y muchos otros). No aconteció lo mismo respecto de los principios emanados de tratados internacionales de protección de derechos humanos hasta que éstos no exhibieron rango constitucional, como se advierte de las diversas precisiones que emergen del relevante precedente "Ekmekdjian" (Fallos: 315:1492). La expansión del tema puede apreciarse en el reciente caso "Q., C. c/Gobierno de la Ciudad”, Fallos: 335:452 relativo al acceso a una vivienda digna por parte de una familia carenciada con un menor discapacitado.

10 Robert Alexy, "Sistema jurídico, principios jurídicos y razón práctica" (del alemán por M. Atienza), Doxa, 5 (1988): 143-144.
} 
principios se trata de la cuestión de qué es debido de manera definitiva, mientras que la solución a una colisión entre valores contesta a qué es de manera definitiva mejor. Principios y valores son por tanto lo mismo, contemplado en un caso bajo un aspecto deontológico, y en otro bajo un aspecto axiológico. Esto muestra con claridad que el problema de las relaciones de prioridad entre principios se corresponde con el problema de una jerarquía de valores" (énfasis del original) ${ }^{11}$.

Ante ello, ingresa otro ingrediente llamado a tener honda repercusión en el horizonte argumentativo. A juicio de Alexy, "la naturaleza de los principios en cuanto mandatos de optimización conduce inmediatamente a una conexión necesaria entre principios y proporcionalidad" 12 , de modo que "la naturaleza de los principios implica el principio de proporcionalidad y viceversa" ${ }^{13}$. No puedo detenerme aquí en el análisis alexyano del principio de proporcionalidad y sus conocidos subprincipios de necesidad, idoneidad y proporcionalidad en sentido estricto (algunos ejemplos jurisprudenciales procurarán ilustrarlo más tarde) más que en lo siguiente : la mayor o menor realización posible de los principios "están determinadas esencialmente por los principios opuestos", por lo que "la determinación del grado apropiado de satisfacción de un principio respecto a lo que ordena otro principio, se determina por medio de la ponderación"14, reconociendo, a ese respecto, una "escala triádica" de intensidades según que la afectación de un principio en un caso concreto sea "leve", "media" o "intensa". La respuesta a esa "gradación” la da, escribe Alexy, la "metáfora del peso" específico de cada principio en un caso concreto, lo que, en cuanto aquí especialmente interesa no está ajeno a una argumentación basada en la necesidad de corrección y en argumentos de carácter moral. A este último respecto, el autor es categórico en cuanto a que, por ejemplo, "la determinación de la intensidad de la interferencia al derecho al honor" de una persona se funda "en la apreciación de dicho epíteto como humillante y como expresión de falta de respeto", lo cual constituye un "argumento moral", sin los cuales, "la fórmula del peso no podría ser aplicable" en ningún caso del estilo por lo que "viene a ser una estructura de la argumentación jurídica y moral" ${ }^{15}$. En este punto, el autor hace frente a la frecuente “objeción de irracionalidad" de la fórmula del peso en tanto "no especifica cómo deben

\footnotetext{
$11 \quad$ Alexy, "Sistema jurídico..., 145.

12 Rabbi-Baldi Cabanillas, "Consideraciones filosófico-jurídicas en torno del Título Preliminar del Proyecto de Código Civil y Comercial de 2012”, en Rivera/Medina, Comentario al Proyecto de Código Civil y Comercial de la Nación 2013 (Buenos Aires: Abeledo Perrot, 2012); Alexy, "Sistema jurídico, principios jurídicos ..., Doxa, 5 (1988); Alexy, "La dignidad humana y el juicio de proporcionalidad” (del inglés por A. García Figueroa), Anuario Parlamento y Constitución, Cortes de Castilla-La Mancha/Universidad de Castilla-La Mancha, 2014, 16, 13.

13 Alexy, "La dignidad humana..., 14.

14 Alexy, "Los derechos fundamentales y el principio de proporcionalidad” (del inglés por J. Portocarrero Quispe), Revista Española de Derecho Constitucional, 91, año 31 (2011): 12.

15 Alexy, "Los derechos fundamentales..., 21.
} 
determinarse los pesos concretos a ser introducidos, medidos y comparados en la fórmula”. $\mathrm{Su}$ respuesta es un decidido alegato, entre otros aspectos, en favor de la relevancia de la argumentación. A su juicio, proposiciones como "la restricción de la libertad de expresión es grave", "tiene que ser justificada" y "esto puede ser hecho solamente mediante argumentos. En este sentido, la fórmula del peso está intrínsecamente conectada con el discurso jurídico", expresando "un argumento básico" de éste ${ }^{16}$. Como tal, añade, "se hace imprescindible para introducir 'orden en el pensamiento jurídico'. Esto pone en claro qué puntos son los decisivos y cómo dichos puntos se relacionan unos con los otros. Una estructura de discurso iusfundamental que asegure mayor racionalidad no es posible. Esto basta para demostrar que el análisis de proporcionalidad es exigido no solamente por la naturaleza de los derechos fundamentales, sino también por la pretensión de corrección misma que a su vez es necesariamente formulada en la argumentación realizada por la jurisdicción constitucional" ${ }^{17}$.

En definitiva, la constitucionalización del ordenamiento jurídico a través del despliegue de los principios jurídicos cuya naturaleza moral es incuestionable ha conducido a que la ciencia jurídica sea vista (es la postura no solo de Alexy, sino de Dworkin, Habermas, Mac Cormick o Finnis) como una práctica institucional de ese carácter. Y, como es obvio, una práctica así entendida requiere no sólo estructurarse en torno de argumentos, sino que, en rigor, precisa de una sofisticada metodología destinada a controlar y a desarrollar el procedimiento argumentativo de modo que éste obtenga soluciones justas.

¿Por qué se requiere de una argumentación? Porque si no la hubiera, ¿cómo cabría persuadir unos a otros acerca de la más pertinente respuesta a una controversia justamente de carácter moral? ¿cómo sustentar los juicios jurídico-morales que tienen entre manos todo operador jurídico? ¿cómo obligar (obligarnos) a explicitar y fundamentar las "precomprensiones", para decirlo con Josef Esser ${ }^{18}$, que cada uno de ellos lleva consigo? ¡cómo "domesticarlas", si se me permite el recuerdo, siempre cautivante, de Saint-Exupery ${ }^{19}$ ? Dicho en palabras de Chaim Perelman: ¿cómo justificar los juicios de valor?, es decir, ¿cómo abordar la racionalidad de los juicios de valor? ${ }^{20}$.

La pregunta de Perelman es, en verdad, la que abre, luego de la Segunda Gran Guerra, los estudios en torno de las diversas teorías de la argumentación jurídica que se han desplega-

\footnotetext{
Alexy, "Los derechos fundamentales..., 17.

Alexy, "Los derechos fundamentales..., Cfr también 17.

18 Josef Esser, Vorverständnis und Methodenwahl in der Rechtsfindung(Frankfurt am Main: Athenäum, 1970), en la que "Vorveständnis" es "precomprensión". Existe traducción castellana del cap. V a cargo de M. Rodríguez Molinero, bajo el título "La Interpretación", Anuario de Filosofía del Derecho, Madrid (1986): 41 ss.

19 Antoine Saint-Exupéry, Le Petit Prince (Paris: Gallimard, 1975).

20 Chaim Perelman, La lógica jurídica y la nueva retórica (Madrid: Civitas, 1988), del francés por L. Díez Picazo, passim.
} 
do desde entonces. Se asiste, pues, a un nuevo paradigma en el que, según se ha adelantado, se abandona la fundamentación positivista basada en el razonamiento lógico-deductivo (discurso apodíctico o demostrativo) para adoptar otra de carácter ponderativo (discurso dialéctico o tópico) con el cual la índole de lo jurídico parece acoplarse mejor en tanto la índole de las cuestiones centrales a las que se enfrenta pertenecen más al mundo de lo verosímil, no de la certeza; de lo probable, no de lo inflexible; de lo razonable, no de lo racional; en suma, de lo que requiere argumentación, no demostración. Dichas cuestiones -ejemplificadas bajo el paradigma que representa el Estado Constitucional de Derecho- requiere de ponderaciones; de ajustes; de delimitaciones que precisan ser explicitados; explicados; desarrollados y, de ordinario, confrontados con otros contenidos nunca en abstracto, sino en el marco de casos concretos, los que acaecen en situaciones precedidas por tradiciones específicas y contextualizadas. En suma, un razonamiento del estilo ha contribuido enormemente -como puntualiza Prieto Sanchís- a "complejizar" las decisiones, lo que no va sin consecuencias respecto de la previsibilidad y seguridad jurídicas, y del papel de la judicatura en la resolución de los conflictos que arriban a sus estrados.

\section{JUDICATURA Y ARGUMENTACIÓN}

Pues bien; en lo que sigue deseo ocuparme de este último aspecto, el que ha concitado una creciente atención -y también preocupación- tanto por los teóricos cuanto por los operadores del derecho.

1. En líneas generales, se observa en diversos aspectos de la práctica tribunalicia el tránsito desde un papel de órgano "reproductor" de las normas, tal y como fue asumido por la Dogmática, a uno de superior actividad, tarea que se emprende básicamente por razones de justicia material y que requiere de un necesario bagaje argumentativo. Así, entre otros ejemplos:

-de pronunciarse sólo ante casos concretos, los jueces han avanzado manifestándose aun en situaciones que han devenido abstractas pero que, por su relevancia institucional, quien se asume como intérprete final de la Constitución considera que debe hacer saber su palabra, a título de autoridad doctrinaria. El también citado caso "Bahamondez" ilustra lo recién expuesto. 
-de considerar que no correspondía declarar de oficio la inconstitucionalidad de las normas, porque ello atenta contra los principios de igualdad de las partes y, precisamente, de auto restricción de los jueces, se avanzó a la postura contraria, con sustento, en lo esencial, en los principios de jerarquía normativa y de iuria novit curia, como se advierte en los casos "Mill de Pereyra y otros"; "Banco Comercial de Finanzas SA (en liquidación BCRA) s/quiebra" y "Rodríguez Pereya, Jorge Luis y otra"21.

-el afianzamiento de la búsqueda de la verdad material por sobre la formal, lo que ha asumido diversas perspectivas que buscan preterir el denominado "exceso ritual manifiesto" en favor de la "verdad jurídica objetiva", tal y como se expresa invariablemente desde el precedente "Colalillo"22; abandonar la obligación del planteamiento de la cuestión federal en la primera oportunidad procesal posible, en favor de su admisión cuando ésta resulta sobreviniente por determinadas circunstancias que así lo justifiquen ${ }^{23}$, o admitir los memoriales federales aun cuando no hubieran seguido los recaudos de presentación exigidos por la Acordada 4/2007 cuando estuvieren en juego determinados principios relevantes, como el derecho a la salud o la persecución de crímenes de lesa humanidad ${ }^{24}$.

De lo expuesto, surgen diversos planteamientos. Por de pronto, una cuestión no menor reside en responder si el intérprete constitucional, esto es, el exégeta de los principios más característicos del ordenamiento jurídico, es todo magistrado (sistema difuso), o son solo algunos de ellos (sistema concentrado) y, en ambos casos, quién y cómo los elige. Es innecesario agregar que los niveles y la extensión de la argumentación variará según las respuestas que se den a estas preguntas.

2. Modelos de jueces. Ejemplos. Dejaré este tema de diseño constitucional para otro momento. Ahora deseo concentrarme en un tópico de índole filosófico jurídico. En efecto; detrás del desafío por el logro de la racionalidad de los juicios de valor por parte de todo decisor late la tensión sea de incurrir en el juez legislador (o quasi legislador), es decir, aquel que con sustento en sus criterios personales crea la solución normativa del caso; sea en el juez mera boca de la ley, esto es, aquel que se erige en el mecánico reproductor de una norma que posee un carácter inflexible, con entera prescindencia de las particularidades de cada supuesto. Es que, frente a tales extremos, en este papel se abogará por la noción aristotélica

\footnotetext{
Cfr., respectivamente, Fallos: 190:142; 302:303; 324:3219; 327:3117 y 335:2333.

Cfr Fallos: 238:550.

23 Cfr, por todos, el completo análisis de Néstor Pedro Sagüés, Recurso extraordinario (Buenos Aires: Astrea, 2, 3ㅇ, 1992), 408-422.

${ }_{24}$ Cfr Corte Suprema de Justicia de la Nación, causas “D., D. F. c/CEMIC s/amparo”, Sent. del 29/4/14, voto del juez Fayt, y causa “A.1320.XLIV. RHE. “Acosta, Jorge E. y otros s/infracción art. 144 bis”, Sent. del 8/4/09”.
} 
del magistrado como sinónimo de "justicia animada” y que aquí se define como el juez intérprete, según se precisará más abajo.

Por de pronto, una pertinente muestra de lo primero es el voto de mayoría de la CIDH en el caso "Artavia Murillo" en el que determina que la vida humana, en el supuesto de las técnicas de fertilización asistida, se inicia recién con la implantación del embrión en el útero materno. El holding del fallo se encuentra en el parág. 186 en el que se lee que "la prueba científica concuerda que (...) si bien el óvulo fecundado da paso a una célula diferente, con la consecuente información genética suficiente para el desarrollo de un ser humano, lo cierto es que si dicho embrión no se implanta en el cuerpo de la mujer sus posibilidades de desarrollo son nulas”25 (énfasis añadido para puntualizar el corazón de la crítica). A mi juicio, deducir la inexistencia de la persona humana por su imposibilidad de desarrollo encierra la propia refutación del postulado, máxime si está contradiciendo la evidencia científica que el propio voto asume de que ya existe una célula diferente, estoy es, que ya hay un ser distinto, más allá de su ninguno, poco o mucho desarrollo posterior. En síntesis, la conclusión parece más bien fruto de un voluntarismo que no resiste las premisas lógicas sobre las que reposa ${ }^{26}$.

A su vez, un ejemplo de lo segundo lo constituye la disidencia parcial del juez Belluscio en la causa "Itzcovich" (Fallos: 328:566) relativa a la planteada inconstitucionalidad del art. 19 de la ley 24.463 en cuanto establece un recurso ordinario de apelación ante la Corte Suprema contra los pronunciamientos de la Cámara Federal de la Seguridad Social. A juicio del magistrado, se trata de una "norma altamente inconveniente que roza los límites de lo absurdo", pues

parece ideada en el propósito de poner trabas al reconocimiento de los derechos previsionales, y ocasiona un singular trastorno en las tareas de este tribunal. Sin embargo, es al legislador a quien incumbe corregir su error, que esta Corte puede señalar, pero no enmendar sin entrar a juzgar del acierto o desacierto de aquél en el ejercicio de sus poderes discrecionales. De lo contrario, se invalidarían las atribuciones del Congreso entrando en el examen del mérito o conveniencia de lo legislado por éste con afectación de la separación y el equilibrio entre los poderes del gobierno federal que el texto constitucional estatuye" (consid. $3^{\circ}$, énfasis añadido para puntualizar el quid del planteamiento citado).

25 CIDH, "Artavia Murillo y ot. (fecundación in vitro) c/Costa Rica", Sent. del 28/11/12, No. 2000-02306, Expediente No. 95-001734-007-CO (expediente de anexos al informe, t. I, folios 88, 90). Una versión abreviada se publicó en La Ley, 28/12/12, p. 8.

26 Para un estudio más detallado del tema, cfr Rabbi-Baldi Cabanillas, R./Fléming Cánepa, E., "El Caso Artavia Murillo vs. Costa Rica de la CIDH: las técnicas de fertilización asistida; el estatuto del embrión y sus efectos en el derecho interno", en Palacio de Caeiro, Silvia (director), Tratados de Derechos Humanos y su influencia en el derecho argentino (Buenos Aires: La Ley, 2015), t. I, cap. XI, 551-595. 
Como surge de lo transcripto, el voto hace gala de una extrema auto restricción en orden al ejercicio de facultades ajenas al Poder Judicial (examinar el modo de ejercicio de una incumbencia de otro Poder), aún a sabiendas de la inconveniencia de la norma y de los graves perjuicios de rango constitucional que irroga a un sector especialmente crítico de la sociedad.

Pues bien, pienso que las teorías argumentativas en sentido lato y el pensamiento de la razón práctica en particular prohíjan un modelo de un "juez intérprete” de todos los hechos arrimados a la causa; todas las razones ( $\mathrm{y}$ sin razones) vertidas en el proceso; todas las normas que integran el ordenamiento jurídico; su jurisprudencia y los aportes doctrinarios que amalgaman, para decirlo con Betti y aún con $\operatorname{Cossio}^{27}$, la tradición jurídica a la que se pertenece y en la que se actúa, de modo que la "norma del caso", según reparaba Karl Engisch, no resulte aquel texto ya escrito ni, tampoco, un documento absolutamente original. Se trata, por el contrario, de arribar a una lectura que sin traicionar su sentido originario, contemple los ingredientes que le aportan la historia; el contexto y las circunstancias de cada caso, actualizando su cabal contenido. En una clave constitucional, cabría decir que se le pide al juez interprete una visión "dinámica" de la norma bajo examen. Ilustraré este punto en el último apartado de este papel.

3. Modelos de casos. Ejemplos. La otra cuestión que deseo plantear aquí y que guarda cierta relación con el perfil de la judicatura que se ha descrito es la clasificación de los casos a los que se enfrenta según sean "fáciles"; "difíciles" o "trágicos". Manuel Atienza escribe que existen casos en los que "cabe establecer una jerarquía más o menos clara de valores, de manera que, por ejemplo, las exigencias que derivan de un valor de rango superior tienen prioridad con respecto a las que derivan de otros de rango inferior". Estos supuestos, es claro, difieren de otros "más graves (...) en que se plantea un conflicto entre valores, o entre exigencias que derivan de valores, que tienen, o cabe plantear que tienen, el mismo rango jerárquico. Esto ocurriría cuando entran en conflicto dos o más derechos 'fundamentales'... ${ }^{22}$. El primer supuesto remite a lo que cabe identificar como un caso "fácil”; el segundo se reconduce a los "difíciles". Ahora bien; cuando dicho procedimiento resguarda la totalidad de los aspectos o elementos que componen cada uno de los derechos fundamentales en tensión, expresa Atienza que se obtiene un "equilibrio óptimo"29. Sin embargo, si ello no es posible (y, como es bien sabido, de ordinario deviene sumamente dificultoso, cuando no imposible que

\footnotetext{
27 Sobre esto, cfr mi estudio "La teoría de la interpretación judicial en Cossio y Betti: coincidencias y actualidad de dos perspectivas contemporáneas”, La Ley, Buenos Aires, 2005-A,1148.

28 Manuel Atienza, "Sobre lo razonable en el derecho", Revista Española de Derecho Constitucional, 9, 27 (1989):.97.

29 Atienza, "Sobre lo razonable..., 100.
} 
lo sea), el equilibrio que resulte será, afirma Atienza, "mínimo" ${ }^{30}$. Por último, cuando nada de eso es viable, se está ante un caso "trágico": "si así ocurriera, entonces no habría forma de encontrar una solución que no sacrificara lo esencial de alguno de los dos valores (...). Ahora no nos encontraríamos ya frente a una simple alternativa, sino frente a un dilema" ${ }^{31}$.

Generalizando, un caso "fácil" tiende a ensamblar con el perfil del juez "boca de la ley", en tanto éste, como mero aplicador de la norma, procura "simplificar" sus resoluciones, sin adentrarse en prescripciones que, en línea de principio, son propias del órgano legislativo. A su turno, los casos "difíciles" y "trágicos" pueden transformarse en el escenario del juez "quasi-legislador" y del juez "intérprete”, en tanto éstos suelen presentar diferencias con la mera subsunción normativa, bien que las razones justificatorias difieren marcadamente: el primero es refractario a obtener resultados antifuncionales con el ordenamiento jurídico; disvaliosos para los fines tenidos en mira por el ordenamiento jurídico o manifiestamente injustos. Por su parte, si bien el juez "quasi legislador" tiende a compartir dichos propósitos, puede no exhibir reservas ni en abandonar el ordenamiento jurídico ni, incluso, las circunstancias fácticas del supuesto al que se enfrente (lo que Alexy denomina "certeza epistémica" ${ }^{32}$ ), lo que no es el caso del anterior, preocupado, según acaba de señalarse en el punto anterior, por hacer honor, conjuntamente, tanto a la semántica cuanto a la finalidad o sentido último del sistema en correspondencia con las circunstancias comprobadas de la causa. Ejemplifico lo recién expuesto con un supuesto que bordea lo "trágico": el caso "FAL" de la Corte Suprema argentina sobre no punibilidad de aborto seguido de violación ${ }^{33}$. El Código Penal argentino vigente autoriza la práctica ante dos supuestos: peligro para la vida y la salud de la mujer sino hubiera otra alternativa menos grave y, transcribo, "si el embarazo proviene de una violación $o$ de un atentado al pudor cometido sobre una mujer idiota o demente" (énfasis añadido). El caso se planteó porque quien requiere la práctica es una menor de edad plenamente capaz, más allá de que el aborto ya se había realizado lo que revela el ya señalado cambio de paradigma desde un juez meramente reproductor de normas a otro más focalizado por discernir el sentido de éstas y, si cabe, su justicia intrínseca. De ahí que, asumido dicho "giro", lo que debe indagarse (y es lo que se hará a propósito de este supuesto en este lugar) es si en ese propósito los magistrados actúan "quasi legisladores” o como "intérpretes”.

\footnotetext{
Atienza, "Sobre lo razonable..., 100.

Atienza, "Sobre lo razonable..., p. 101.

Alexy, "La dignidad humana...", p. 24.

Sobre este tema, cfr más ampliamente mi estudio "El aborto no punible en la Argentina: consideraciones sobre el sentido de la norma permisiva y prospectivas desde una filosofía del derecho constitucional, a partir del caso "F." de la Corte Suprema”, Pensar en derecho, número 0, año 1 (año), Facultad de Derecho, Universidad de Buenos Aires, 331-378.
} 
La mayoría de la Corte resolvió que le asiste razón con sustento en que "al utilizar una conjunción disyuntiva” (la “o”) el legislador “previó dos supuestos diferentes”. Pues bien; dicha afirmación no solo contradice la semántica de la norma (el Diccionario de la Real Academia esclarece que la "o" tiene valor tanto disyuntivo como coordinante), sino que, ante la razonable duda de cuál sentido gramatical corresponde asignar a la conjunción, se debió acudir -como el Alto Tribunal lo recuerda constantemente en invariable jurisprudencia, menos en ésta ocasión- a la voluntad del legislador y, en este caso, todavía más, existía la posibilidad de acudir a la fuente que sirve de base al texto, el anteproyecto suizo de 1917, sin contar, a mayor abundamiento, con los comentadores del documento más clásicos, tanto los de entonces como posteriores, de todo lo cual se hubiera concluido que la exención solo cubría a la mujer idiota o demente y ello con sustento en tristemente célebres motivaciones eugenésicas, que fueron explícitamente señaladas en los fundamentos de ambas normas (la suiza y la argentina). La mayoría del tribunal, pues, actuó en el caso como "quasi legislador", a contramano de la voluntad expresa del legislador penal; de otras normas constitucionales, infraconstitucionales y de una metodología interpretativa de armonización de los derechos fundamentales que el propio órgano exige adoptar de ordinario.

Por el contrario, el voto concurrente de los jueces Petracchi y Argibay parece encaminarse en la línea de lo que cabría considerar el “juez intérprete”. Por de pronto, reconoce que se está ante una "severo conflicto de intereses" entre derechos de análogo rango (el del nasciturus y el de la mujer), algo que no había sido considerado en el anterior voto el que, por tanto, plantea la cuestión del aborto en términos de un "derecho" (absoluto) de la mujer. De seguido, señala que la defensa del nasciturus no ha probado que las "medidas alternativas" que propicia para evitar la práctica neutralicen el perjuicio que sufre la peticionante (voto de la jueza Argibay, consid. 13, párr. $4^{\circ}$; voto del juez Petracchi, consid. 11, la cursiva se ha añadido), por lo que, a contrario, parece sugerir que de haberlo hecho, no procedería el pedido.

A mi juicio, lo expuesto está revelando que para estos magistrados el supuesto bajo análisis entraña un caso "trágico" ("Sólo en consideración de este contexto específico ["peligro para un interés legítimo" de la mujer] es que el legislador acepta como socialmente soportable una conducta que en sí aprecia como prohibida" (voto de la jueza Argibay, consid. 14, párr. $1^{\circ}$ ) que, de ser posible, debe evitarse, y de no serlo podría autorizarse el aborto, pero no con sustento en lo que la ley claramente no dice, sino, v. gr., con apoyo en la hipótesis del peligro para la vida o salud de la mujer.

Se advierte, en fin, que el resultado podría ser semejante pero la estructura argumental difiere por completo: el juez de la mayoría actuó como un "quasi-legislador” en tanto que: 
a) prescindió de la norma infraconstitucional aplicable al caso -art. 86, inc. $2^{\circ}$, Cód. Penal-; b) ignoró la categórica voluntad legislativa; c) omitió acudir a la metodología de interpretación ponderativa de los derechos en tensión, la que es reemplazada, según se vio, por una jerarquización de valores y principios que, finalmente, d) conducen a una desconsideración de los aspectos fácticos del caso. Por el contrario, el voto concurrente parece acercarse a la lógica del "juez intérprete" en tanto evidencia un acatamiento al sentido último de las normas en juego (al reconocer la existencia de una "extrema conflictividad" entre dos derechos de primer orden ${ }^{34}$ ); revela la consideración, a contrario, de la "certeza epistémica" de la causa (de haber probado la defensa del nasciturus la existencia de medidas alternativas menos gravosos que el aborto) y -aspecto éste dirimente- a través del empleo de una método que ubica en la cúspide valorativa a todos los derechos constitucionales involucrados en cada caso, considera que éstos no exhiben prioridad de rango ni en abstracto ni en concreto: en lo primero, porque ningún derecho prevalece sobre otro (no "pesa" más la vida y la salud psico-física de la madre que la del nasciturus o viceversa); en lo segundo, porque la tarea del intérprete es garantizar, tanto como resulte posible, la concreción de los derechos en tensión a niveles de equilibrio cuanto menos "mínimos", para seguir el planteamiento de Atienza, reservando el "dilema" del caso "trágico" (la necesidad de optar por uno u otro derecho como última ratio del ordenamiento jurídico y luego de haber agotado el análisis de todas las posibilidades fáctico jurídicas en orden a evitarlo.

4. El aporte de las teorías argumentativas a la justificación racional de las decisiones. Algunas consideraciones. En este horizonte de especial complejidad, considero que en la actualidad la judicatura cuenta con suficientes elementos como para asumir exitosamente la función de lo que aquí se ha llamado el juez intérprete gracias al creciente nivel de sofisticación y completitud asumido por los convergentes esfuerzos de las teorías argumentativas. Éstas se han ido concibiendo como una perspectiva "moral procedimental del discurso práctico racional" en la que "un enunciado normativo es correcto o verdadero cuando es el resultado de un determinado procedimiento, es decir, el del discurso racional"35. Dicho discurso se nutre de un haz de reglas orientadas a controlar las valoraciones ínsitas en toda decisión ya que "es imposible un sistema de reglas metódicas que establezca exactamente sólo un resultado". Sobre el particular, Alexy añade -y cualquier práctico del derecho no puede sino rendirse ante la evidencia- de que "en todos los casos ya medianamente dudosos se requieren valoraciones" de suerte que "la racionalidad del procedimiento de aplicación

Cfr voto de la jueza Argibay, consid. 13, párr. $2^{\circ}$ y voto del juez Petracchi, consid. 10.

35 Robert Alexy, "La idea de una teoría procesal de la argumentación jurídica", en Garzón Valdés (comp.), Derecho y filosofia (Barcelona, Alfa, 1985), 44. 
del derecho depende si y en qué medida" dichas reglas "son accesibles a un control racional" ya que las mismas no entrañan ninguna determinación sobre convicciones normativas. De ahí que, avance el autor, la presencia de un haz de reglas no solamente desnuda inconsistencias en aquellos razonamientos que prescinden de ellas, sino que garantiza la racionalidad (corrección) de los enunciados; la racionalidad de la argumentación y la justificación de la decisión ${ }^{36}$. No corresponde en este papel el análisis (ni siquiera elemental) de cuál es ese conjunto de reglas (generales y específicas) del discurso práctico jurídico racional que, en la terminología alexyana, elaboran un "código de la razón práctica" que permite controlar y, en definitiva, configurar juicios sustentados bajo una pretensión de verdad o corrección ${ }^{37}$, labor que ha sido realizada con especial profundidad y claridad por otros autores a los que se remite $^{38}$ y que, por cierto, la Corte Suprema ha sido emplear aquí y allá39. Además de lo que al respecto diré en el último apartado de este capítulo, deseo ahora efectuar dos precisiones complementarias al papel de las teorías argumentativas en la difícil tarea de discernimiento del sentido último de lo justo.

La primera es que estos planteamientos no parten de cero. En efecto; existen condiciones limitadoras" que son antiguas y forman parte de nuestra práctica más acendrada ("la sujeción a la ley; la obligada consideración de los precedentes; su encuadre en la dogmática elaborada por la ciencia jurídica organizada institucionalmente (...), las reglas del ordenamiento procesal" ${ }^{\prime 40}$.

La segunda precisión es que, a pesar de sus denodados empeños, estos planteamientos no impiden la existencia de criterios encontrados. Se trata de una afirmación de la mayor relevancia. El autor lo denomina "posibilidad discursiva" ${ }^{41}$ ya que reconoce que el

36 Robert Alexy, Teoría de la argumentación jurídica. La teoría del discurso racional como teoría de la fundamentación jurídica, Centro de Estudios Constitucionales, Madrid, 1989 (del alemán por M. Atienza e Isabel Espejo), nota 31, 279-280.

37 Alexy, Teoría de la argumentación jurídica, p. 36.

$38 \mathrm{Cfr}$, entre otros, los completos estudios de José Antonio Seoane, "Un Código ideal y procedimental de la razón práctica. La teoría de la argumentación jurídica de Robert Alexy”, en Pedro Serna (Dir.), De la argumentación jurídica a la hermenéutica. Granada: Ed. Comares, 2005; nota 54, pp. 105-195; Serna, Filosofía del derecho y paradigmas epistemológicos. De la crisis del positivismo a las teorías de la argumentación jurídica y sus problemas, Porrúa, México, 2006, pp. 78-103; Rodolfo Luis Vigo, "La teoría jurídica no positivista de Robert Alexy”, en él mismo, La injusticia extrema no es derecho (de Radbruch a Alexy, La Ley, Buenos Aires, 2004, pp. 25-72 y, de modo general, el colectivo que reúne doce estudios sobre el pensamiento de Alexy/Alonso/Rabbi-Baldi Cabanillas, Argumentación..., nota 32, passim.

39 Me he ocupado de ello en "El principio de proporcionalidad, la dignidad humana y la jurisprudencia de la Corte Suprema. Un análisis desde la perspectiva de Robert Alexy”, en Alexy, Robert/Alonso, Juan Pablo/Rabbi-Baldi Cabanillas, Argumentación..., nota 32, pp. 231-254 (reproducido en "Jurisprudencia Argentina”, Buenos Aires, 2017-I, 12, pp. 1-12). A su vez, preparo un estudio respecto de la jurisprudencia que jurisprudencia en que denuncia casos de discriminación a propósito de las denominadas "categorías sospechosas".

40 Alexy, Teoría de la argumentación..., p. 36.

41 Alexy, Teoría de la argumentación..., 202. 
procedimiento no prescribe las premisas normativas de partida de los participantes en el discurso, las que pueden, por ende, diferir ${ }^{42}$, de donde -como es obvio- subsiste la posibilidad de justificar dos enunciados incompatibles pese a ser rigurosamente fundados, sin infringir las reglas del discurso.

Como es obvio, esta "posibilidad discursiva" nada dice en perjuicio de las teorías de la argumentación. Antes bien, parece dar cuenta de su nota esencial y, por ende, tanto de sus límites cuanto de sus potencialidades. Por de pronto, conviene reparar que la inexistencia de una "seguridad jurídica" asumida en la clave del pensamiento positivista clásico no es equivalente a irracionalidad pues, además de que -se insiste- "no es la producción de seguridad lo que constituye el carácter racional de la Jurisprudencia, sino el cumplimiento de una serie de condiciones, criterios o reglas" ${ }^{43}$, el derecho, como se había anticipado, no es un concepto concluido de una vez y para siempre, sino una realidad que se configura caso a caso en el marco de un quehacer eminentemente práctico. En ese sentido, la ausencia de una "respuesta correcta" no implica que ésta no exista como "idea regulativa"; como "idealiter"; como "pretensión de corrección" que el operador jurídico configura, tanto como le resulta posible, en cada caso con el concurso de todos los elementos y factores de que dispone la ciencia jurídica, la que, por cierto, no es ajena a una "tradición", la que actúa no como un mero repertorio de datos, sino que procura explicar o, mejor, y para decirlo de manera hermenéutica, "comprender" el destino del ser humano al cual el derecho ha de servir si es que quiere encontrar su razón de existir ${ }^{44}$.

\footnotetext{
42 Alexy, Teoría de la argumentación..., p. 273: "el punto de partida del discurso lo constituyen las convicciones normativas realmente existentes, que con frecuencias son incompatibles entre sí".

43 Alexy, Teoría de la argumentación..., nota 31, p. 279.

44 Por eso dice Alexy que en la tarea el jurista no está solo, sino que se haya acompañado de un ordenamiento social racional y justo, el que debe integrarse tanto en una teoría del derecho (cuyo valor medular es la racionalidad), como en una teoría del Estado (cuyo valor es la democracia y los derechos humanos). De ahí que, añada, la "teoría del discurso es coherente con el estado democrático occidental y expresa la idea de la libertad y de la igualdad universal”. Considero que esta afirmación asume un dato fáctico (la primera parte) y emite un juicio teórico (la segunda). Esta última es relevante por su pretensión de generalidad que, a mi ver, es lo característico de toda teoría del discurso: si éstas no tienen como norte alcanzar un entendimiento universal, verdaderamente habrán fracasado. En esa línea, más allá de que puedan identificar mejor a Occidente que a otras regiones (afirmación que pongo entre paréntesis), considero que las teorías argumentativas constituyen el prius para un entendimiento universal. Por eso, completa Alexy, la teoría del discurso jurídico racional "como tal ideal, apunta más allá del campo de la jurisprudencia. Los juristas pueden, ciertamente, contribuir a la realización de la razón y de justicia, pero esto, en el sector que ellos ocupan, no pueden realizarlo aisladamente. Ello presupone un orden social racional y justo” (Teoría de..., p. 280).
} 


\section{UN EJEMPLO VIRTUOSO DE ARGUMENTACIÓN}

Deseo ahora retomar el caso "Itzcovich" pero a través de sus votos mayoritarios, en razón de que en ellos encuentro un adecuado ejemplo de una argumentación robusta que, distanciándose tanto del "juez boca de la ley" cuanto del "juez legislador" (al que uno de los votos mayoritarios -el del juez Lorenzetti- refiere críticamente en su pronunciamiento), hace honor a los exigentes postulados del Estado Constitucional de Derecho, cuidando, al mismo tiempo, que aquella argumentación no resulte defraudada ni por una lectura originalista del documento ni, tampoco, mediante una descontextualización de aquél a través de una mirada ajena a sus raíces propias.

Como se puntualizó, en esa causa se discutía la inconstitucionalidad del art. 19 de la ley 24.463, lo que así fue declarado por el Alto Tribunal a través de tres votos concurrentes que, a mi ver se estructuran en niveles crecientes y complementarios de argumentación proporcionando una fundamentación lo más completa y satisfactoria posible respecto de la decisión adoptada.

El voto mayoritario (jueces Petracchi; Fayt y Highton), recuerda, en primer lugar, los motivos que inspiraron el dictado de la ley bajo análisis (moderar el altísimo índice de litigiosidad en la materia; evitar el dispendio jurisdiccional y, en cuanto concierne al art. 19, considerar que la tercera instancia ordinaria tuvo en miras conceder una mayor seguridad de acierto a los fallos atenta su repercusión en asuntos análogos, consids. $6^{\circ}$, in fine y $7^{\circ}$ ).

Sobre tales bases, precisa las objeciones que "la evidencia empírica” muestra respecto del procedimiento del citado artículo: (a) "gran expansión en el ámbito de competencia de la Corte, tanto en el aspecto cuantitativo como en la diversidad de temas fácticos y jurídicos que ha debido abordar, con la consiguiente alteración del rol que venía cumpliendo como intérprete final de la Constitución Nacional" (b) inadecuado empleo de dicha vía por parte del Estado Nacional, en tanto "la experiencia reflejada en las estadísticas demuestra" que "una significativa mayoría de los recursos ordinarios" deducidos fueron rechazados o declarados desiertos"; (c) lo que ha entrañado "una injustificada postergación" en el cobro de créditos de carácter alimentario.

Ante ello, concluye que "si bien es cierto que hasta el presente la Corte acató la jurisdicción reglada (...) ello no la inhabilita para declarar que la disposición impugnada, aunque no ostensiblemente incorrecta en su origen, ha devenido indefendible”, con sustento en un triple orden de razones: (a) "no se adecua a los fines tomados en consideración para 
su sanción y en su aplicación"; (b) en su aplicación práctica compromete "el rol institucional del máximo tribunal” y (c) "causa graves perjuicios a los justiciables en una etapa de la vida en que la tutela estatal resulta imprescindible" (consid. 10).

Se advierte el ingreso de la dimensión ponderativa en el razonamiento del voto: la norma, no "ostensiblemente" incorrecta al inicio, sí lo es ahora con sustento en la desvirtuación tanto de los "fines" planteados (fines éstos que se estructuran como mandatos de optimización de determinados objetivos, en el caso, el acceso a una jubilación integral -derecho constitucional de primer rango- por lo que, se ańade en el consid. 11, se "justifica adoptar el criterio que más convenga a la celeridad del juicio" -confr. también consid. 13-), cuanto de los "medios" escogidos para el logro de aquellos (los que, como es obvio, también son susceptibles de un análisis en términos de la mayor o mejor adecuación) (confr., también, consid. 10).

El horizonte ponderativo se corrobora cuando se alude al principio de "razonabilidad", el cual, a juicio de los jueces, entraña que "debe cuidarse (...) que los preceptos mantengan coherencia con las reglas constitucionales durante todo el lapso que dure su vigencia” (criterio que, por lo demás, se vincula con una de la regla de la teoría argumentativa alexyana de la fundamentación del origen de las convicciones normativas, las que deben superar la prueba de su génesis histórico crítica ${ }^{45}$ ), por lo que, a la luz de lo expuesto, "corresponde concluir" que la norma bajo análisis "carece actualmente de la racionalidad exigida por la Ley Fundamental", máxime si se desvirtúan mediante su aplicación otros "enunciados de jerarquía constitucional” (consids. 10 y 13).

El voto concurrente de los jueces Maqueda y Zaffaroni mantiene los criterios recién expuestos, bien que profundiza algunos de ellos y añade otros. Si se pensara en la idea hermenéutica de "espiral argumentativo", cabría considerar que este voto incorpora un nivel más sofisticado de análisis, en tanto aporta nuevas perspectivas que coadyuvan a una mejor fundamentación del thema decidendum ${ }^{46}$.

Así, en el consid. $4^{\circ}$, tras afirmar el cambio de criterio del tribunal, precisa, en línea con la más prístina tradición de la razón práctica, que "a esta Corte no incumbe emitir juicios históricos, ni declaraciones con pretensión de perennidad, sino proveer justicia en los casos concretos que se someten a su conocimiento". Y profundizando sobre esa mutación de parecer, en el consid. $7^{\circ}$ expresa, con apoyo en lo resuelto en el célebre precedente "Kot", que aquella acaece "con el transcurso del tiempo y el cambio de circunstancias objetivas re-

45 Cfr, al respecto, Seoane, "Un código ideal...", 134.

46 Cfr sobre el punto, el breve estudio "La espiral hermenéutica" de Arthur Kaufmann en él mismo, Hermenéutica $y$ derecho, edición a cargo de A. Ollero y J. A. Santos (Granada: Comares, 2007), 141-145. 
lacionadas con ellas". Todavía más: en el siguiente considerando, reconociendo la peculiar función constitucional del Tribunal, expresa que ésta "lo lleva a ponderar cuidadosamente las circunstancias, evitando que por aplicación mecánica e indiscriminada de la norma se vulneren derechos fundamentales de la persona y se prescinda de la preocupación por arribar a una decisión objetivamente justa en el caso concreto, lo que iría en desmedro del propósito de ‘afianzar la justicia’, enunciado en el Preámbulo...” ya que "la misión judicial (...) no se agota en la remisión a la letra de la ley, toda vez que los jueces (...) no pueden prescindir de la ratio legis y del espíritu de la norma; ello por considerar que la admisión de soluciones notoriamente disvaliosas no resulta compatible con el fin común tanto de la tarea legislativa como de la judicial".

Se han enfatizado expresiones características de aquella tradición: mirada al caso concreto como reflejo del referido "pensamiento problemático"; relevancia de las circunstancias “objetivas", es decir, no de cualquier elemento a la hora de alterar un criterio antes admitido o de introducir uno nuevo, todo lo cual, como es claro, conduce a prescindir de una "aplicación mecánica" o literal de las normas favoreciendo, en su lugar, el ya referido razonamiento ponderativo que, en rigor, profundiza en el sentido último del documento (su teleología). Es que el propósito que anima la tarea judicial es el logro de los valores constitucionales, uno de los cuales es el afianzamiento de la justicia, para lo cual, en línea con la reflexión antes citada de Viola, se ha de buscar más que la letra legal, el sentido genuino de ésta.

El voto retoma la distinción fines-medios ya vista en el anterior, precisando que si bien "en principio no es una cuestión sobre la que deba pronunciarse la magistratura", lo será si se advierte una clara inadecuación entre éstos (consids. $9^{\circ}$ y 10). La conclusión afirmativa se impone con sustento en las razones ya dadas aunque el voto incorpora otras.

Así, pide que el art. 19 objeto de controversia "sea ponderado en relación con lo dispuesto en el art. 75, inc. 22 de la Constitución Nacional” (consid. 17), es decir, propicia una interpretación "de conformidad" con diversas disposiciones de la Ley Suprema expuestas en convenciones internacionales que reclaman, en esencia, la pronta conclusión de los asuntos.

Asimismo, efectúa un "análisis más pormenorizado” a través de "la pauta de control prevista en el art. 28" del texto supremo (consids. 19-27). El sugerente estudio realizado en esos considerandos, a cuya lectura se reenvía, incluye algunas interesantes reflexiones que memoran el planteamiento alexyano, anteriormente citado. Así, el Alto Tribunal reconoce que 
quizá juzgar la racionalidad absoluta de un acto no sea tarea humanamente posible, incluso al mero nivel de adecuación de medios a fines, dada la imposibilidad de prever toda la causalidad que cada acto humano desata o altera, pero no cabe duda de que es humanamente posible juzgar la irracionalidad manifiesta, la inadecuación completa e incluso paradojal respecto del principio proclamado" (consid. 27).

Sobre tales bases, el voto concluye que el cuestionado art. 19 "si bien proviene del uso de la competencia legislativa otorgada por los arts. 117 y 75, inc. 32 constitucionales, lo hace sobrepasando el límite impuesto por el art. 28, quedando fuera del específico diseño institucional" (consid. 28) ya que, en otra remisión en la que sobrevuela tanto la tradicional jurisprudencia de la Corte sobre la materia ${ }^{47}$ cuanto la autoridad de Alexy, aquél artículo "no resulta un medio ni adecuado, ni idóneo, ni necesario, ni proporcional en relación con los derechos, intereses y valores que el Estado está llamado a proteger en la materia bajo examen” (consid. 30).

Por último, el voto del juez Lorenzetti, incorpora otras argumentaciones que, sumadas a las de los votos precedentes, proporcionan una mirada sumamente completa de la resolución bajo examen. Así, reconoce la necesidad de aquella incorporación cuando expresa que si bien el conflicto bajo análisis "quedaría suprimido por la garantía que los tribunales de grado dan en la especie, que haría innecesaria no sólo la vía cuestionada, sino todo debate al respecto por un principio de economía argumentativa", agrega "que no obstante ello, cabe desarrollar otros argumentos para reforzar el valor persuasivo de la sentencia desde el punto de vista de los valores y de la lógica jurídica constitucional que surge de la interpretación armónica de los arts. 28, 75, incs. 22 y 23 de la Carta Magna” (consid. 10, énfasis añadido).

A mi ver, esos argumentos se refieren al especial estatuto del sector de la sociedad afectado por la norma cuestionada, y a la índole y alcance de la decisión asumida y en ellos no se escatima un expreso recurso a la filosofía jurídica, en orden a aportar una fundamentación lo más robusta posible de la solución de especie.

Para lo primero menciona la "A Theory of Justice" del ya citado Rawls para justificar lo que en el derecho constitucional norteamericano se conocen como "affirmative actions" que, como es sabido, se expanden al derecho comparado arribando con la reforma de 1994 a nuestro texto supremo. Así, recuerda que "un principio de justicia que goza de amplio consenso es aquel que manda desarrollar las libertades y los derechos individuales hasta el

\footnotetext{
47 Cfr, por todos, Juan Cianciardo, El principio de razonabilidad. Del debido proceso sustantivo al moderno juicio de razonabilidad (Buenos Aires, Ábaco, 2004), passim.
} 
nivel más alto compatible con su igual distribución entre todos los sujetos que conviven en una sociedad dada, así como introducir desigualdades excepcionales con la finalidad de maximizar la porción que corresponde al grupo de los menos favorecidos". Y agrega que esto es lo que acaece en nuestra Constitución a través de los arts. 16 y 75, inc. 23, párrafo $1^{\circ}$. Sobre tales bases -en un razonamiento que, además, implícitamente memora a Alexy cuando señala que "si el legislador constituyente ha superado una colisión de principios expidiendo una regla, entonces el principio formal de autoridad de la Constitución exige que esa regla sea respetada" ${ }^{48}$-, concluye que "la calificación constitucional de los ancianos como un grupo particularmente vulnerable, incorpora una regla hermenéutica que no se compadece con la introducción de diferencias que, lejos de protegerlos, desmejoran su posición jurídica” (consid. 11) que es, precisamente, lo que acaece con la norma cuestionada, motivo por el cual se justifica su declaración inconstitucionalidad.

El segundo aspecto - la declaración de inconstitucionalidad a la que se arriba- conduce al voto a expresar, en el consid. 13, que "es necesario precisar el criterio que se utiliza" sobre el particular "a fin de contribuir a la seguridad jurídica", motivo por el cual debe diferenciarse claramente la interpretación adaptativa, la inconstitucionalidad sobreviniente y la descalificación por los efectos derivados de la aplicación de una norma jurídica”. En todos los casos, la argumentación cabalga sobre criterios que son propios de la tradición de la razón práctica. Así, se lee que la primera consiste "en adjudicar un sentido a la norma jurídica y por ello, tratándose de conceptos jurídicos indeterminados, puede perseguir una legítima concretización a las circunstancias de tiempo y lugar (...) pero de ninguna manera importa su descalificación y expulsión del sistema jurídico”. Es claro: conceptos del estilo -en rigor, se trata de tópicos o de tipos (typus $)^{49}$ - requieren ser concretados en cada caso bajo el prisma constitucional por lo que adquieren un alcance que varía, enriqueciéndose con los ingredientes del texto supremo, el que no los expulsa, sino que los cobija bajo su seno.

La segunda "ha sido utilizada para invalidar una regla afectada por las transformaciones históricas y sociales". Y añade: "ésta es una alternativa excepcionalísima dentro de la ya excepcional declaración de inconstitucionalidad", ya que "si las mudanzas de opinión o los cambios de costumbres o de políticas gubernamentales de una década a otra fueran el único sustento para reinterpretar los textos constitucionales y descalificar las leyes, de modo ordinario o habitual, se incurriría en un relativismo extremo, que lesionaría gravemente la seguridad jurídica de los ciudadanos". Las expresiones subrayadas, de inocul-

${ }^{48} \quad$ Alexy, "Los derechos fundamentales...", 26. 1976).

Kaufmann, Analogía y naturaleza de la cosa. Hacia una teoría de la comprensión jurídica (Chile: Jurídica de Chile, 
table trascendencia, aleccionan contra lo que más arriba se ha caracterizado como el "juez legislador"

Por último, la descalificación de la ley por sus efectos es precisada cuando se dice que "los constituyentes decidieron sujetarse a unos principios fundamentales para convivir en sociedad", los que han sido "expresados con sabia amplitud, para permitir la adaptación a los tiempos futuros", por lo que conviene hacer especial hincapié en que "no debe confundirse la indeterminación lógica con la valorativa”. Pues bien, éste último es el test que no resiste el art. 19 bajo análisis pues esa norma, "a lo largo del tiempo de su aplicación demostró un efecto contrario al que ella misma perseguía y al sistema de valores y principios constitucionales". Es que, de nuevo con la referida regla alexyana de la génesis "histórico crítica”, expresa que "el elemento a considerar no es sólo el contexto de sanción de la norma, sino el de aplicación, de modo que pueda ser sometida a una prueba de verificación de la permanencia de su adaptación constitucional”.

\section{CONCLUSIÓN}

Espero que las páginas precedentes hayan aportado alguna luz al estimulante debate al que se asiste en torno del tópico de la argumentación jurídica. He querido discurrir, a partir de ciertos elementos que aporta la filosofía jurídica, en la riqueza que proporciona la jurisprudencia constitucional, acaso el "teatro de operaciones" por excelencia en el que confluyen las reflexiones teórico-prácticas que a diario nos fatigan. El caso que se ha examinado en el apartado anterior -uno de tantos que podrían haberse escogido para su análisis- enseña las virtudes y los riesgos que entrańa tornar realidad los exigentes recaudos que caracterizan el Estado Constitucional de Derecho del que hoy se goza. Este Estado sintetiza centurias de reflexiones y de luchas en favor, para decirlo kantianamente, de quien "no puede ser usado meramente como medio" de modo que a su respecto queda limitado "todo capricho (y es un objeto de respeto)" ${ }^{50}$. Se trata de un alto listón que no debe ser infravalorado ni, menos, dejado a un lado por el no menos variado, complejo y exigente despliegue argumentativo que, como se ha procurado poner de relieve, lleva ínsito ese Estado Constitucional de Derecho: éste, en rigor, solo se entiende y solo será si las sociedades complejas y en muchos casos

50 Immanuel Kant, Fundamentación de la metafisica de las costumbres (Madrid: Espasa Calpe, 1983) (del alemán por M. García Morente),85. 
fragmentadas en las que hoy vivimos ${ }^{51}$ son capaces de explicitar; estructurar; fundamentar y persuadir argumentaciones que únicamente tengan en miras la defensa del destinatario de esas reflexiones y de esas luchas.

Para citación: Rabbi-Baldi Cabanillas, Renato, "Mirada argumentativas y filosóficas ante casos difíciles”, en Revista de Derecho N 19 (jul.-2019), ISSN 1510-3714, ISSN On line 2393-6193, 77-102

Contribución 100\% Renato Rabbi-Baldi Cabanillas.

\section{BIBLIOGRAFÍA}

Alexy, Robert, "La dignidad humana y el juicio de proporcionalidad", Anuario Parlamento y Constitución, Cortes de Castilla-La Mancha/Universidad de Castilla-La Mancha, 2014.

Alexy, Robert, "La idea de una teoría procesal de la argumentación jurídica”, en Garzón Valdés (comp.), Derecho y filosofía. Barcelona: Alfa, 1985.

Alexy, Robert, "Los derechos fundamentales y el principio de proporcionalidad", Revista Española de Derecho Constitucional, 91, año 31 (2011).

Alexy, Robert, "Sistema jurídico, principios jurídicos y razón práctica”, Doxa, 5 (1988).

Alexy, Robert, Teoría de la argumentación juridica. La teoría del discurso racional como teoría de la fundamentación jurídica. Madrid: Centro de Estudios Constitucionales, 1989.

Atienza, Manuel, "Sobre lo razonable en el derecho", Revista Española de Derecho Constitucional, 9, 27 (1989).

Cianciardo, Juan, El principio de razonabilidad. Del debido proceso sustantivo al moderno juicio de razonabilidad. Buenos Aires, Ábaco, 2004.

Esser, Josef, Vorverständnis und Methodenwahl in der Rechtsfindung. Frankfurt am Main: Athenäum, 1970.

Hart, Herbert, "El nuevo desafío al positivismo jurídico", Sistema N 36 (mayo 1980), Madrid.

Kant, Immanuel, Fundamentación de la metafísica de las costumbres. Madrid: Espasa Calpe, 1983.

\footnotetext{
51 Tomo esta idea de los constitucionalistas Peter Häberle y Gustavo Zagrebelski, habiéndolas desarrollado en mi discurso de ingreso a la Academia Nacional de Ciencias Morales y Políticas, "Universalismo vs. multiculturalismo en la encrucijada contemporánea de los derechos humanos. Algunos ejemplos históricos y recientes de la jurisprudencia argentina”, editado por esa Academia, Buenos Aires, vol. 40, 2014,15-55.
} 
Kaufmann, Arthur, Analogía y naturaleza de la cosa. Hacia una teoría de la comprensión juridica. Chile: Jurídica de Chile, 1976.

Kaufmann, Arthur, Hermenéutica y derecho, edición a cargo de A. Ollero y J. A. Santos. Granada: Comares, 2007.

Larenz, Karl, Metodología de la ciencia del derecho. Barcelona: Ariel, 2001

Perelman, Chaim, La lógica jurídica y la nueva retórica. Madrid: Civitas, 1988.

Rabbi-Baldi Cabanillas, R.-Fléming Cánepa, E., "El Caso Artavia Murillo vs. Costa Rica de la CIDH: las técnicas de fertilización asistida; el estatuto del embrión y sus efectos en el derecho interno", en Palacio de Caeiro, Silvia (director), Tratados de Derechos Humanos y su influencia en el derecho argentino. Buenos Aires: La Ley, 2015, t. I, cap. XI, 551-595.

Rabbi-Baldi Cabanillas, Renato, “Consideraciones filosófico-jurídicas en torno del Título Preliminar del Proyecto de Código Civil y Comercial de 2012”, en Rivera/Medina, Comentario al Proyecto de Código Civil y Comercial de la Nación 2013. Buenos Aires: Abeledo Perrot, 2012.

Rabbi-Baldi Cabanillas, Renato, "El principio de proporcionalidad, la dignidad humana y la jurisprudencia de la Corte Suprema. Un análisis desde la perspectiva de Robert Alexy”, Jurisprudencia Argentina, 12 (2017-I): 1-12.

Rabbi-Baldi Cabanillas, Renato, "La teoría de la interpretación judicial en Cossio y Betti: coincidencias y actualidad de dos perspectivas contemporáneas", La Ley, Buenos Aires, 2005-A,1148.

Rabbi-Baldi Cabanillas, Renato: Las razones del derecho natural. Perspectivas teóricas y metodológicas ante la crisis del positivismo jurídico. Buenos Aires: Ábaco, 2008.

Sagüés, Néstor Pedro, Recurso extraordinario. Buenos Aires: Astrea, 2, 3º, 1992.

Saint-Exupéry, Antoine de, Le Petit Prince. Paris: Gallimard, 1975.

Seoane, José Antonio, “Un Código ideal y procedimental de la razón práctica. La teoría de la argumentación jurídica de Robert Alexy”, en Serna, De la argumentación...

Serna, Pedro (Dir.), De la argumentación jurídica a la hermenéutica. Granada: Ed. Comares, 2005.

Serna, Pedro, Filosofía del derecho y paradigmas epistemológicos. De la crisis del positivismo a las teorias de la argumentación juridica y sus problemas. México: Porrúa, 2006.

Viehweg, Theodor, Tópica y Filosofía del Derecho. Barcelona: Gedisa, 1991.

Vigo, Rodolfo Luis, La injusticia extrema no es derecho (de Radbruch a Alexy). Buenos Aires: La Ley, 2004. 